\title{
GESTÃO DOS RESÍDUOS SÓLIDOS DE INDIANÓPOLIS - MG
}

\author{
Lílian Carla Moreira Bento ${ }^{1}$
}

( 1 - Licenciada em Geografia pela Universidade Federal de Uberlândia e Especializando em Gestão Ambiental pela Faculdade Católica de Uberlândia Rua Oliveira Lima, 1050, Pampulha, Cep 38408-650, Uberlândia - MG, liliancmb@yahoo.com.br)

\section{Resumo:}

A partir do advento da Revolução Industrial, a população mundial teve seu modo de vida revolucionado por um acelerado e intenso processo de urbanização e industrialização. Estes acontecimentos exigiram o consumo crescente de produtos menos duráveis, culminando na maior geração de lixo. Este trabalho tem por objetivo analisar a gestão do lixo produzido em Indianópolis-MG. Para isso, se correlacionou dados secundários pertinentes ao tema com dados primários obtidos através de trabalhos de campo na área de disposição final do lixo, aplicação de questionários com os moradores da área urbana e realização de entrevista com o prefeito, visando identificar a percepção ambiental que esses atores têm do problema em questão. Essa pesquisa é o resultado parcial do trabalho de conclusão de um curso de especialização e é matéria-prima para um posterior projeto de educação ambiental.

Palavras-chave: Gestão pública, lixo, educação ambiental, Indianópolis.

\begin{abstract}
:
Solid Waste Management in Indianópolis - Brazil

From the advent of the Industrial Revolution, the world-wide population had its way of life revolutionized for one sped up and intense process of urbanization and industrialization. These events had demanded the crescent consumption less durable products, culminating in the generation bigger garbage. This job has for objective to analyze of the management of the produced garbage in Indianópolis-MG(Brazil). In such case, correlated if it given secondary pertinent to the subject with gotten primary through fieldwork in the final area of disposal of the garbage, application of questionnaires with the inhabitants of the urban area and accomplishment of interview of the one with the mayor, aiming at to identify the ambient perception that these actors have of the problem in question. This research is the partial result of the job of conclusion of a specialization course and is raw material for a posterior project of ambient education.
\end{abstract}

Key-words: civil service, garbage, ambient education, Indianópolis. 


\section{1 - Introdução}

A partir da Revolução Industrial, a população mundial passou por um acelerado e intenso processo de urbanização e industrialização. Estes acontecimentos revolucionaram a vida da população, provocando uma expressiva mudança nos seus hábitos. Desde então, as pessoas passaram a conviver, entre outras, sob a ditadura do tempo, tendo que viver e produzir num ritmo desenfreado. Esse novo ritmo de produção provocou o surgimento da chamada era dos descartáveis, de forma a facilitar o novo estilo de vida da sociedade. Porém, o uso contínuo desse tipo de produto exerce uma pressão maior sobre os recursos naturais, além de produzir um volume abundante de lixo.

Só no Brasil, cada pessoa produz de 500 a 850 gramas de lixo por dia e das cidades brasileiras com sistema de limpeza urbana, aproximadamente $71 \%$ dispõem o lixo nos lixões. (OLIVEIRA, 2002).

Essa destinação do lixo simboliza uma dificuldade do poder público realizar corretamente e de forma satisfatória o saneamento básico, considerando também "o acelerado processo de urbanização, aliado ao consumo crescente de produtos menos duráveis e/ou descartáveis.” (COMPROMISSO EMPRESARIAL PARA A RECICLAGEM, 2000, p.8).

O lixo aparece atualmente, portanto, como um dos grandes desafios para as autoridades públicas e sociedade. Todos esses personagens do cenário mundial devem se preocupar e agir coletivamente, pois o lixo não é só um problema ambiental e de saúde, como resultado de diversas disfunções sócio-econômicas que urgem em serem resolvidas.

Diante disso, nos propomos a identificar e analisar a gestão do lixo produzido no município de Indianópolis, indicando o local e os impactos gerados pela disposição desse material. Além disso, a percepção ambiental que a população do município tem desse problema será exposta, de forma a conduzir um posterior trabalho de educação ambiental.

Esta pesquisa foi desenvolvida baseando-se na análise de dados secundários através de levantamento bibliográfico pertinente ao tema e mediante a geração de dados primários executando-se trabalhos de campo na área de disposição do lixo, aplicação de questionários à uma amostra aleatória de 131 pessoas que residem na área urbana e entrevista com o prefeito do município, identificando-se o desenvolvimento de algum projeto na área em questão. A análise e correlação dos dados secundários e primários foram de suma importância para se delinear a questão do lixo no município de Indianópolis - MG. 


\section{2 - Indianópolis e o Manejo dos Resíduos Sólidos}

O município de Indianópolis se situa no Triângulo Mineiro, oeste de Minas Gerais e faz divisa com os municípios de Araguari, Nova Ponte, Uberlândia, Uberaba e Estrela do Sul, como mostra a figura 1.

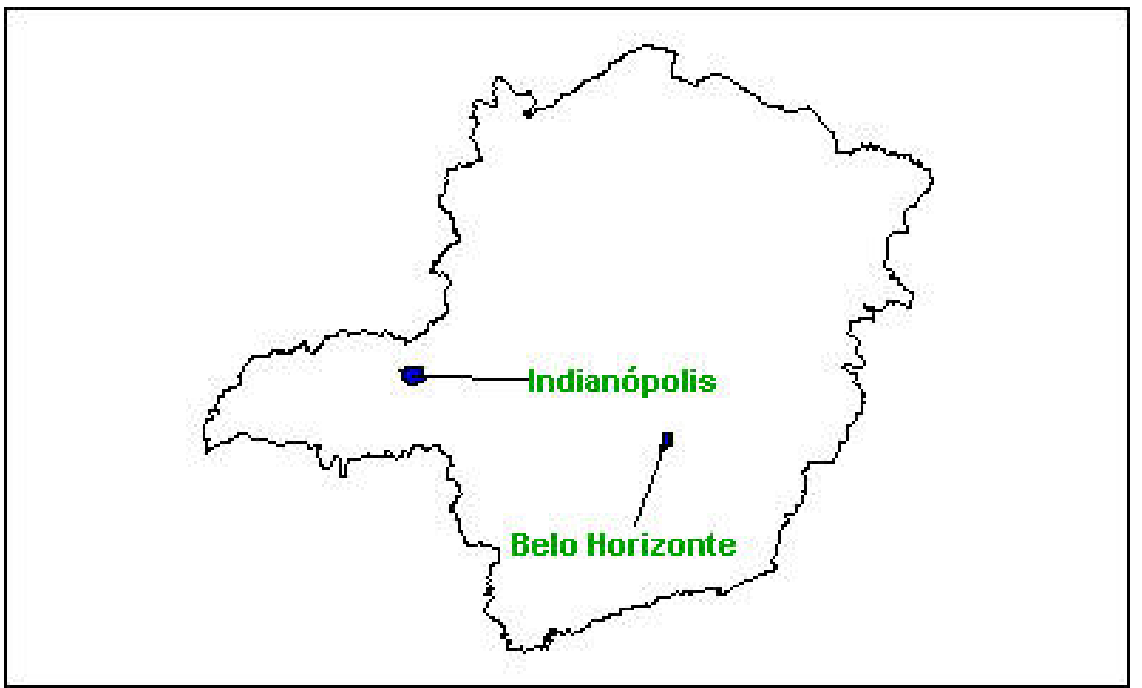

Figura 1 - Localização de Indianópolis - Fonte: IBGE

Com cerca de 5710 habitantes, 3500 destes morando na área urbana, o município passou por um discreto processo de urbanização na década de 90, mas é o setor primário que ainda emprega boa parte da população. (IBGE, 2000).

Parte dessa população também trabalha na cidade, sendo em média 430 pessoas contratadas pela Prefeitura Municipal e algumas destas prestando serviço na área de limpeza pública do município. Esse serviço conta com a capina, varrição e coleta dos resíduos domiciliar, hospitalar, público, comercial, agrícola e entulho, correspondendo a um gasto mensal de R\$10.000,00.

Resíduos sólidos são todos os resíduos nos estados sólido e semi-sólido, que resultam das atividades da comunidade, de origem: industrial, doméstica, hospitalar, comercial, agrícola, de serviços e de varrição. (ABNT apud CONSELHO NACIONAL DO MEIO AMBIENTE - CONAMA, Resolução $\mathrm{N}^{0} 5$, de 5 de agosto de 1993)

O lixo produzido na área urbana de Indianópolis é coletado no período da manhã por um pequeno caminho compactador, durante cinco dias da semana (segunda, terça, quinta, sexta e sábado). O lixo coletado é constituído por uma variada gama de materiais: plásticos, garrafas PET, papel e papelão, latas de alumínio, isopor, pneus e restos de alimentos, alguns extremamente tóxicos e poluentes como é o caso das pilhas, lâmpadas fluorescentes, tintas, agrotóxicos entre outros. 


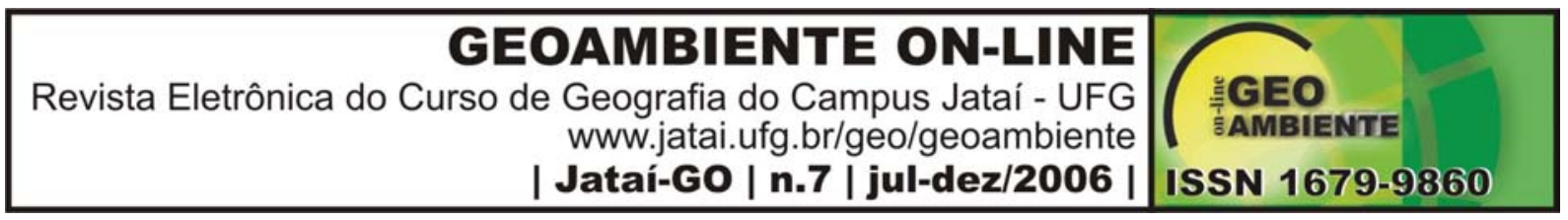

Com a progressiva preocupação com a qualidade ambiental e saúde das comunidades, se criou uma legislação ambiental específica para resíduos mais tóxicos e poluentes, é o caso das pilhas, baterias e pneus. Todavia, podemos perceber que em muitos municípios, como em Indianópolis, não é dado à esse tipo de material uma destinação final adequada.

O CONAMA (Resolução No 308, de 21 de março de 2002) também prevê um licenciamento ambiental compatível à realidade dos pequenos municípios (com população urbana até 30 mil habitantes e geração diária de até 30 toneladas de lixo), mas em Indianópolis todo esse material ainda é depositado em um lixão localizado a aproximadamente $3 \mathrm{~km}$ da cidade, saída para a BR-365. Esse lixão, situado em uma área da Prefeitura Municipal de Indianópolis, se encontra envolto por uma vegetação de cerrado e está a cerca de 400 metros de um curso d'água.

Segundo o COMPROMISSO EMPRESARIAL PARA A RECICLAGEM (2002), lixão é uma forma inadequada de disposição final dos resíduos sólidos municipais, caracterizando-se pela simples descarga sobre o solo, sem medidas de proteção ao meio ambiente ou à saúde pública.

O lixão de Indianópolis não foge à essas regras, apresentando uma série de deficiências de ordem sanitária e ambiental, além de problemas de ordem operacional.

Os problemas operacionais são:

- 200 metros de vias de acesso sem pavimentação, o que dificulta o deslocamento em épocas de chuva,

- falta de controle da área (ausência de cercas e vigilância, presença de catador),

- descontrole dos resíduos recebidos,

- ausência de critérios para a disposição do lixo (servidores não usam equipamento de segurança e higiene).

Quanto às de ordem sanitária podemos citar:

- mau cheiro,

- vetores de doenças (cães, gatos, ratos, urubus, moscas, mosquitos, bactérias, fungos etc.).

Já as deficiências ambientais verificadas no local são: 
- poluição visual,

- desmatamento,

- poluição do solo,

- mau cheiro,

- produção de chorume, principalmente, em épocas de chuva.

Essas são algumas das características do lixão de Indianópolis, verificadas através de um trabalho de observação. Um estudo mais aprofundado, com análise do solo, por exemplo, pode apontar outras, como contaminação do lençol freático pelo chorume.

É interessante ressaltar que essa é a situação do atual lixão de Indianópolis. Esse local tem em média seis anos, mas o município já teve outros três lixões que foram aterrados e, inclusive, dois deles, que hoje se situam dentro do perímetro urbano, estão sendo loteados para famílias de baixa renda, sem nenhum estudo prévio de contaminação da área.

\section{3 - A Questão do lixo sob a ótica dos moradores de Indianópolis}

A população selecionada para compor a amostra desta pesquisa apresenta as mais variadas características, apresentadas nas figuras 2, 3 e 4 .

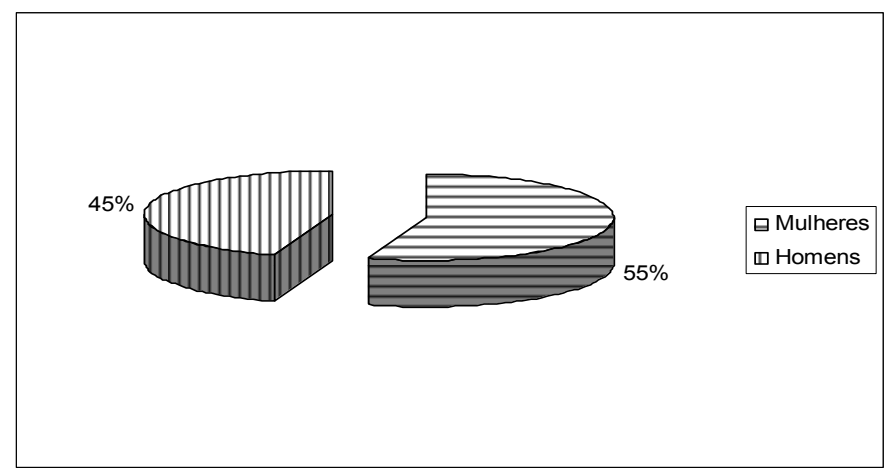

Figura 2 - Sexo dos entrevistados.Fonte: Pesquisa de Campo - 2006. 


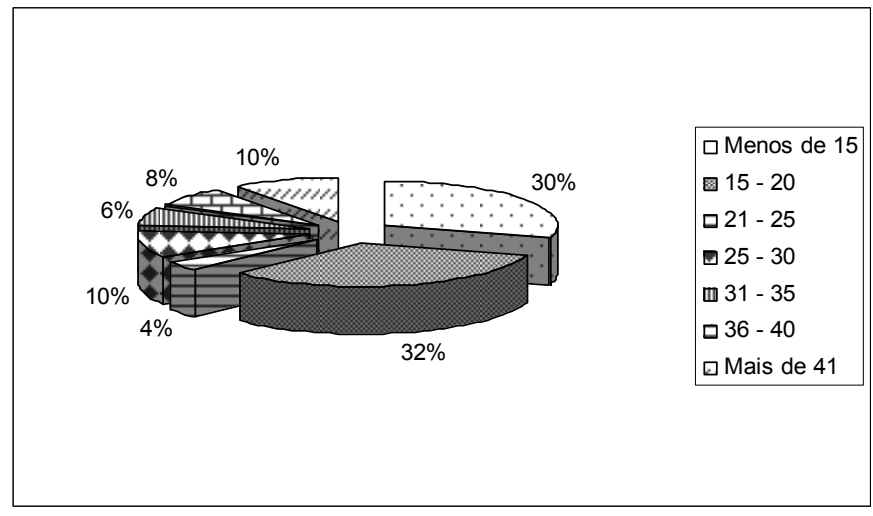

Figura 3 - Faixa etária dos entrevistados.Fonte: Pesquisa de Campo - 2006.

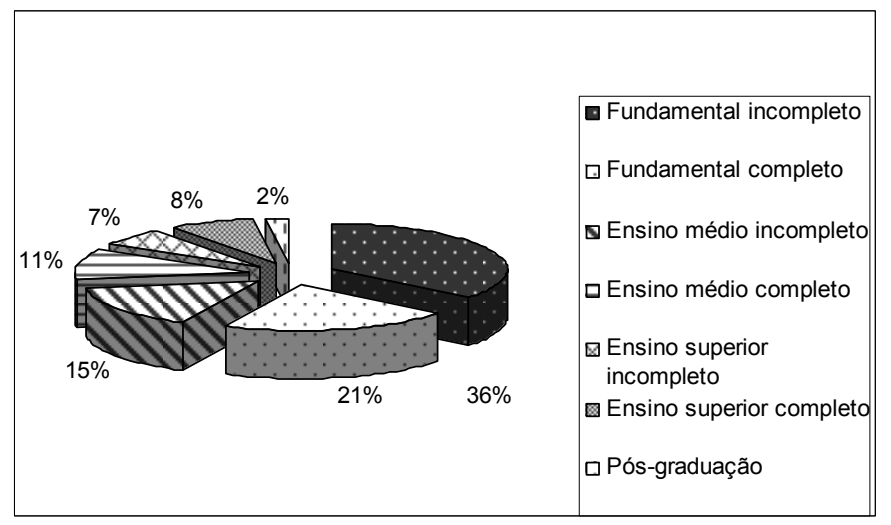

Figura 4 - Grau de escolaridade dos entrevistados. Fonte: Pesquisa de Campo - 2006.

A presente pesquisa revelou que, apesar da heterogeneidade da população indianapolense amostrada, a mesma percebe de forma crítica a gestão dos resíduos sólidos produzidos no município. De acordo com $89 \%$ dos entrevistados, os lixões ocasionam impactos ambientais como poluição do solo e lençol freático, mau cheiro, desmatamento entre outros. Além de causar problemas de saúde, sendo locais de proliferação de animais nocivos e transmissores de doenças.

Eles também reconhecem que a questão do lixo não é um problema só das autoridades públicas. Segundo $75 \%$ dos entrevistados, a responsabilidade é tanto do poder público como da sociedade. Cabe ao poder público manter a cidade limpa através de um sistema de limpeza urbana organizada e eficaz, tanto como dispor adequadamente o lixo e conscientizar a população. Já a sociedade deve ser parceira do poder público, colaborando para o sucesso da limpeza urbana e se educando, exercendo sua cidadania de forma a não só cobrar para que seus direitos sejam assegurados, mas cumprindo com seus deveres.

O poder público é o responsável direto pelo problema do lixo, mas deve mobilizar a sociedade para buscar parcerias no sentido de minimizar os efeitos (Pesquisa de Campo, 2006). Versões como essas demonstram, portanto, que a população sabe que deve colaborar 
com a gestão correta do lixo e que uma das principais formas de se atingir esse objetivo é realizando-se a educação ambiental.

Através da educação ambiental continuada as pessoas mudam comportamentos e passam a trazer para o convívio doméstico este aprendizado (Pesquisa de Campo, 2006) . Educação essa que precisa ocorrer em todas as esferas, inclusive no setor público que deve ser o disseminador de idéias e práticas mais sustentáveis, pois "qualquer programa de gestão integrada de resíduos deverá prever um trabalho de sensibilização e mobilização dos diversos setores da sociedade, através de ações de educação ambiental.” (BADUE, 1999, p. 197).

O prefeito de Indianópolis, quando indagado sobre esse assunto, também diz concordar com a população que o sistema de limpeza urbana do município apresenta muitas falhas, que é preciso dar um destino ambientalmente correto ao lixo e que a educação ambiental é um passo importante e necessário para a adoção de novos hábitos de vida. Inclusive, ele alega que a prefeitura já vem sendo penalizada, através de multas, pelo fato de dispor inadequadamente o lixo em lixões, mas também tem buscado reverter essa situação e que a FUNASA - Fundação Nacional de Saúde - liberou uma verba de R\$159.000,00 para a construção de uma usina de reciclagem. A única pendência para a construção da mesma é o espaço físico, já que estão tendo dificuldades de encontrar uma área disponível. Com relação à melhoria da limpeza urbana e desenvolvimento de projetos de educação ambiental, estes terão que esperar, pois não são considerados como prioridades. No momento, a prefeitura está quitando dívidas da gestão passada e resolvendo problemas de infra-estrutura, moradia para famílias carentes, construção de uma clínica hospitalar e outros. (Pesquisa de Campo, 2006)

\section{4 - Considerações Finais}

Indianópolis é um pequeno município de Minas Gerais que apresenta uma gritante dificuldade de gerir os resíduos sólidos que produz. Essa dificuldade é percebida devido à inadequada disposição que dá ao seu lixo, carregando em sua história a tradição de criar lixões, apresentando três passivos ambientais por conta disso.

Tal situação não passa desapercebida pela população que, insatisfeita com o quadro atual, sugere a criação de um local com condições sanitárias e ambientais corretas para a destinação final do lixo. Além disso, as autoridades públicas devem praticar ações simples, como informar os dias e horários em que ocorrem a coleta do lixo.

Apesar da população, insatisfeita, cobrar por melhorias e se ver disposta a colaborar, se integrando, entre outros, em programas de cunho ambiental, é possível identificar a discrepância na fala e no modo de agir das pessoas. Faz parte do hábito delas jogarem lixo no 


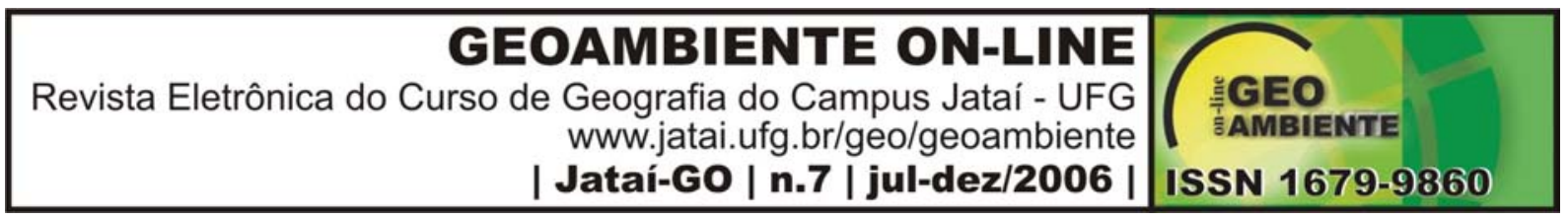

chão, não o embalar corretamente antes de colocá-lo no cesto e a dificuldade que têm de reciclar ou reutilizar os materiais descartados.

Sendo assim, a atual situação do lixo produzido em Indianópolis é, não só um reflexo de uma administração pública ineficaz e sua tradicional postura de relegar as questões ambientais para última instância, como de uma cidadania pouco exercida e que se pauta muito mais no plano das idéias do que na própria mudança de atitude.

Diante deste contexto, é preciso que esses dois atores de fato se cooperem, colocando em prática uma legislação pertinente ao tema e exercendo uma educação ambiental que deve ser disseminada dos mais novos aos mais velhos, em todas as partes da sociedade.

Cabe, portanto, ao poder público gerenciar adequadamente seu lixo, desenvolvendo ações organizadas e prioritárias conforme indica o COMPROMISSO EMPRESARIAL PARA A RECICLAGEM (2002):

$1^{\mathrm{o}}$ : Coletar todo o lixo,

$2^{\circ}$ : Adequar a destinação final do lixo, seja através de um aterro sanitário ou, no mínimo, controlado,

$3^{\mathrm{o}}$ : Buscar formas de segregação e tratamento do lixo,

$4^{\text {o: }}$ Desenvolver campanhas e programas voltados à sensibilização e conscientização da população,

$5^{\mathrm{o}}$ : Incentivar medidas que visem diminuir a geração de lixo.

Com relação às duas últimas ações, as autoridades devem buscar parcerias com os diversos núcleos sociais para que, paralelamente a adequação da área para a disposição do lixo, a população seja instruída e tenha condições de reeducar seus hábitos através da educação ambiental.

Considerando que uma das máximas pregadas pela educação ambiental é a redução do lixo produzido, a reciclagem é um importante tema a se trabalhar. A reciclagem deve partir inicialmente da coleta seletiva na Prefeitura Municipal de Indianópolis e esta, servindo de exemplo e experiência, se estenderia ao restante da comunidade. Dessa forma, quando a usina de reciclagem estiver operando a população já estará instruída e a possibilidade de um sucesso será maior.

"A reciclagem, a coleta seletiva e a mobilização da cidadania em torno do problema do lixo são questões eminentemente culturais, daí a importância de realizar-se esse tipo de projeto nas escolas, nos bairros, nos locais de trabalho.” (SIRKIS, 1999, p. 131).

A reeducação da sociedade e do poder público, assim como a instalação de um local mais adequado ao lixo de Indianópolis não são atitudes que frutificarão a curto prazo. Essas 
ações são um investimento a longo prazo, que demandam tempo, capital e força de vontade de todos os envolvidos, devendo sempre serem revistas e estimuladas de modo que, com o passar do tempo, os resultados possam ser sentidos e a qualidade ambiental e de vida da população sejam melhoradas.

\section{5 - Referências Bibliográficas}

BADUE, A. F. B., BARCIOTTE, M. L. Minimização de resíduos: passaporte sustentável para o século XXI. In: EMPRESA BRASILEIRA DE CORREIOS E TELÉGRAFOS, FUNDAÇÃO PREFEITO FARIA LIMA. O município no século XX: Cenários e perspectivas. Edição especial. São Paulo: [s.n.], 175-183p. 1999.

BRASIL. Ministério do Meio Ambiente, dos Recursos Hídricos e da Amazônia Legal. O que o brasileiro pensa sobre o meio ambiente, desenvolvimento e sustentabilidade. Brasília, 20 p. 1997.

BENTO, L. C. M. Diagnóstico do manejo de resíduos sólidos domiciliares em Indianópolis $M G$, (em fase de elaboração). Trabalho de Conclusão de Curso (Especialização) - Faculdade Católica de Uberlândia, Uberlândia, 2006.

CAVInAtTo, V. M., RODRIGUES, F. L. Lixo: de onde vem? Para onde vai? São Paulo: Moderna, 95 p. 2003.

COMPROMISSO EMPRESARIAL PARA A RECICLAGEM. Instituto de pesquisas tecnológicas do Estado de São Paulo. Lixo municipal: manual de gerenciamento integrado. São Paulo: [s.n.], 370 p.2000.

CONSELHO NACIONAL DO MEIO AMBIENTE - CONAMA. Resolução $N^{o} 001$, de 25 de abril de 1991. Regulamenta a criação de uma Câmara Técnica Especial para analisar, emitir parecer e encaminhar ao Plenário do CONAMA, a proposta de alteração da Portaria n ${ }^{\circ}$ 053/79 no que se refere à questão dos resíduos de qualquer natureza gerados no país. Disponível em: $<$ http://www.conama.br>. Acesso em: 10 jun. 2006.

. Resolução $N^{o} 5$, de 5 de agosto de 1991. Regulamenta o gerenciamento dos resíduos sólidos gerados nos portos, aeroportos, terminais ferroviários e rodoviários e estabelecimentos prestadores de serviços de saúde. Disponível em: <http://www.conama.br>. Acesso em: 10 jun. 2006.

Resolução $N^{\circ} 308$, de 21 de março de 1999. Estabelece critérios e procedimentos para o licenciamento ambiental em municípios de pequeno porte, de unidades de disposição final de resíduos sólidos e para obras de recuperação de áreas degradadas pela disposição inadequada dos resíduos. Disponível em: <http://www.conama.br>. Acesso em: 10 jun. 2006. 
. Resolução $N^{o} 257$, de 30 de junho de 1999. Regulamenta a destinação final a ser dada às pilhas e baterias. Disponível em: <http://www.conama.br>. Acesso em: 10 jun. 2006.

. Resolução $N^{o} 258$, de 26 de agosto de 1999. Regulamenta a destinação final a ser dada aos pneumáticos inservíveis. Disponível em: <http://www.conama.br>. Acesso em: 10 jun. 2006.

FRANÇA, M. N, PINHEIRO, M. S. F., SILVA, A. M. Guia para normalização de trabalhos técnicos científicos: projetos de pesquisa, trabalhos acadêmicos, dissertações e teses. 5. ed. Uberlândia: UFU, 2005. 144 p.

INSTITUTO BRASILEIRO DE GEOGRAFIA E ESTATÍSTICA. Resultados da amostra do Censo Demográfico 2000. Disponível em: <http://www.ibge.br>. Acesso em: 10 jun. 2006.

LIMA, L. M. Q. O tratamento do lixo. São Paulo: Hermus, 240 p. 1985.

OLIVEIRA, J. F. Guia pedagógico do lixo. São Paulo: Secretaria de Meio Ambiente. 90 p. 2002.

SIRKIS, A. Lixo. In: . Ecologia urbana e poder local. Rio de Janeiro: [s.n.]. cap. V, p. 109-134. 1999. 